\section{Phân tích hiệu quả của móng bè - cọc}

\section{Hoàng Công Vũ ${ }^{1 *}$, Phan Ngọc Sơn ${ }^{1}$}

${ }^{1}$ Khoa Kỹ thuật \& Công nghệ, Trường Đại học Quy Nhơn, 170 An Dương Vương, Tp. Quy Nhơn, Bình Định

\begin{tabular}{ll}
\hline TỪ KHOÁ & TÓM TĂT \\
Mộ số nền & Bài báo này phân tích hiệu quả kinh tế của móng bè - cọc so với móng cọc khoan nhồi. Sau khi dùng \\
& phương pháp xét đến mồi quan hệ tương hồ giữa đất, bè, cọc và mô hình bài toán bằng phần mềm ETABS \\
và SAFE đem lại hiệu quả đáng kể khi so sánh móng bè - cọc với móng cọc khoan nhồi.
\end{tabular}

\section{KEYWORDS}

Piled raft foundation

Coefficients of the floor

\section{ABSTRACT}

This paper analyzes the economic efficiency of piled raft foundation compared to the bored pile foundation. After using the method to consider the interrelationships between soil, rafters, piles and problem modeling by ETABS and SAFE software, there is a significant efficiency when comparing raft pile foundation with bored pile foundation.

\section{Giới thiệu}

Ở Việt Nam hiện nay khi thiết kế móng bè - cọc thường có hai quan điểm là đơn giản về hệ cọc chịu (xem như cọc chịu hoàn toàn tải của công trình) hoặc hệ bè chịu (xem như bè chịu hoàn toàn tải của công trình). Quan điểm thiết kế thứ nhất thiên về an toàn nhưng không kinh tế, nên chỉ áp dụng khi công trình có yêu cầu cao về khống chế độ lún. Quan điểm thiết kế thứ hai, móng bè trên nền thiên nhiên là phương án kinh tế nhưng độ lún của bè rất lớn và thường nền đất không đủ sức chịu tải với công trình có tải trọng lớn. Hai quan điểm này có ưu điểm là các bước tính toán áp dụng các lý thuyết kết cấu thông dụng, đơn giản. Nhưng phương pháp này không đúng với điều kiện làm việc thực tế của công trình, không tận dụng hết khả năng chịu lực của kết cấu cũng như đất nền. Kết quả là sử dụng vật liệu nhiều hơn so với các phương án móng khác.

Để thay đổi quan điểm chưa chính xác về móng bè - cọc, các chuyên gia cơ đất đã tìm cách đưa ra các lý thuyết tính toán hệ thống móng này, trong đó có Poulos (1994) [4] đã áp dụng phương trình Midlin của bán không gian đàn hồi vào trong bài toán bè - cọc và những thử nghiệm thực tế để phân tích ngược (back analysis) bài toán này, Poulos đã đưa ra một mô hình gần với thực tế. Mô hình này đã được chấp nhận rộng rãi, được áp dụng để xây dựng nhiều công trình và tiếp tục được phát triển. Tương tác giữa cọc - bè - đất nền ảnh hưởng lớn đến ứng xử của bè - cọc sẽ được xem xét dựa trên phân tích bằng phương pháp phần tử hữu hạn.

Với đề tài "Phân tích hiệu quả của móng bè - cọc" sẽ cung cấp tài liệu cần thiết cho sinh viên và Kỹ sư ngành Xây dựng trong việc tính toán thiết kế tối ưu móng bè - cọc các công trình ngoài thực tiễn,

\footnotetext{
"Tác giả liên hệ: hcvu@ftt.edu.vn

Nhận ngày 01/05/2021, giải trình ngày 12/05/2021, chấp nhận đăng 13/07/2021
}

đặc biệt là các công trình khu vực địa chất ở Thành phố Quy Nhơn tỉnh Bình Định.

\section{Cơ sở lý thuyết}

Cho đến nay có rất nhiều các giả thuyết khác nhau về nền nhưng giả thuyết Winkler được dùng nhiều hơn cả. Phương pháp hệ số nền Winkler đã và đang được sử dụng rộng rãi trên thế giới nhất là ở Mĩ và các nước tây Âu. Mô hình nền Winkler hay còn gọi là mô hình nền biến dạng cục bộ, điều đó cho phép coi nền đàn hồi gồm các lò xo độc lập và cường độ phản lực của đất tại mỗi điểm tỉ lệ bậc nhất với độ lún đàn hồi tại điểm đó thông qua hệ số nền đàn hồi Ks không đổi cho mỗi loại đất (Hình 1).

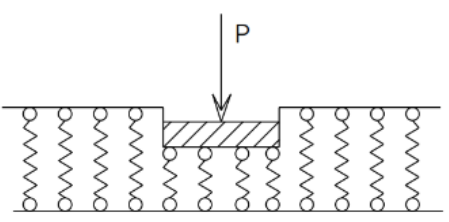

Hình 1. Mô hình nền Winkler.

Đặc điểm của mô hình này là chỉ xét đến biến dạng đàn hồi ngay tại nơi có tải trọng ngoài tác dụng, mà không xét đến biến dạng đàn hồi của đất ở vùng lân cận, bỏ qua đặc điểm đất như một vật liệu có tính dính và tính ma sát. Mô hình biến dạng tương ứng với lý thuyết này là một nền đàn hồi gồm hệ lò xo có biến dạng luôn luôn tỷ lệ với áp lực tác dụng lên chúng.

Độ cứng lò xo $\mathrm{K}$, với $\mathrm{K}=\mathrm{Ks.F}$, trong đó Ks là hệ số nền đặc trưng cho mỗi loại đất, $\mathrm{F}$ là diện tích phần ảnh hưởng của mặt đáy móng với nút đang xét, theo quy tắc phân phối trung bình [1]. 
Mô hình nền Winkler có ưu điểm là đơn giản, tiện dụng trong tính toán, có thể sử dụng những phần mềm phần tử hữu hạn có sẵn, thiết kế gần đúng với thực tế, đặc biệt là những nền đất yếu, có lực dính và ma sát nhỏ, khi đó ảnh hưởng của vùng lân cận xung quanh vùng chịu tải nhỏ, có thể bỏ qua.

Đặc điểm điểm nổi bật của móng bè - cọc là sự ảnh hưởng tương hổ giữa đất và kết cấu móng trong quá trình chịu tải theo bốn hướng ảnh hưởng sau:

- Sự tương tác giữa cọc và đất;

- Sự tương tác giữa cọc và cọc;

- Sự tương tác giữa đất và móng bè;

- Sự tương tác giữa cọc và móng bè;

Sơ đồ tính móng bè - cọc: Bè được mô hình bằng phần tử tấm, liên kết với các lò xo đặc trưng cho cọc và cho đất. Cọc được thay thế bằng một liên kết lò xo có độ cứng phụ thuộc vào chuyển vị cọc dưới tác dụn của tải trọng công trình. Thay thế đất nền bằng các liên kết lò xo tại các điểm sao cho phù hợp với sự thay đổi của đất nền và tính chất làm việc của cọc (Hình 2).

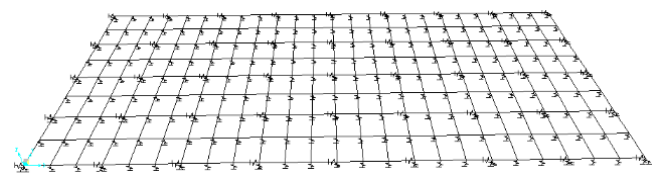

Hình 2. Mô hình tính toán móng bè - cọc.

\section{Ví dụ minh họa}

\subsection{Bài toán 1}

Xét công trình VĂN PHÒNG LÀM VIỆC, số 63 Trần Anh Tông, thành phố Quy Nhơn, tỉnh Bình Định. Công trình này gồm 10 tầng, có kích thước mặt bằng $(16,9 \times 7,97) \mathrm{m}$, nằm trên nền đất có lớp 1 : Lớp đất đắp phế thải xây dựng (sét, á sét, cát dăm) cao từ $1-1,5 \mathrm{~m}$, lớp 2: lớp cát thô ( màu vàng nhạt, xám trắng) chiều dày 16 - 17,5 m, lớp 3 : lớp sét (màu xanh, vàng nhạt) dày 10 - 14,5 m, lớp 4: lớp cát ( cát mịn, cát thô vừa) chiều dày chưa xác định. Mặt bằng bố trí cọc khoan nhồi (39 cọc, $\mathrm{D}=0,5 \mathrm{~m}, \mathrm{~L}=17 \mathrm{~m}$ ) (Hình 3).

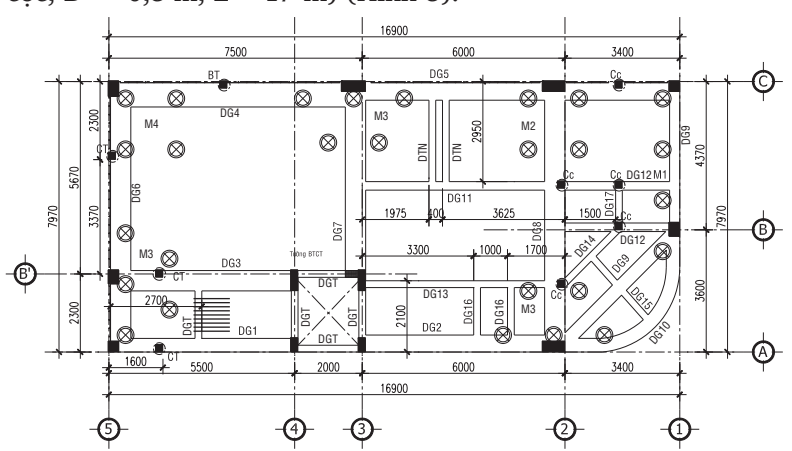

Hình 3. Mặt bằng bố trí móng cọc khoan nhồi Văn phòng làm việc.
- Công trình được mô hình 3D trong phần mềm ETABS 17 (Hình 4).

- Xuất toàn bộ phản lực chân cột, tổ hợp tải trọng, khai báo vật liệu từ phần mềm ETABS.

- Lưu dưới dạng file SAFE.F2K để Import vào phần mềm SAFE V16.

- Mô hình móng bè - cọc trong SAFE V16 theo dạng bè phẳng (Hình 5).

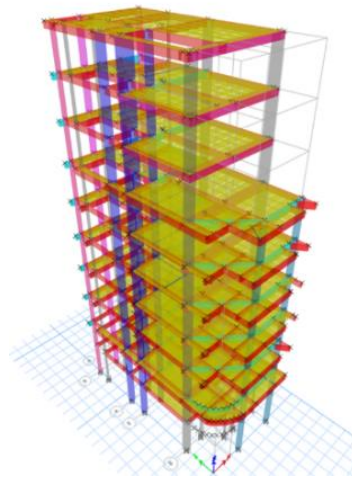

Hình 4. Mô hình 3D công trình Văn phòng làm việc.

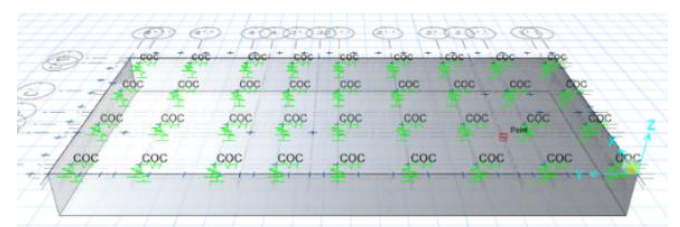

Hình 5. Mô hình móng bè - cọc công trình Văn phòng làm việc.

\subsection{Bài toán 2}

Xét công trình KHÁCH SẠN CANARY, số 94 Xuân Diệu, thành phố Quy Nhơn, tỉnh Bình Định. Công trình này gồm 20 tầng, có kích thước mặt bằng $(15 \times 19,95) \mathrm{m}$, Địa tầng từ mặt đất hiện trạng xuống đến $66 \mathrm{~m}$ có 7 lớp đất: Lớp 1 lớp đất đắp có chiều dày từ 1-2,2 m; lớp 2: lớp cát có chiều dày từ 8,5 - 8,6 m; lớp 3: lớp bùn á sét có chiều dày từ 3,5 -4,2 m; lớp 4: lớp bùn sét có chiều dày từ $33-35 \mathrm{~m}$; lớp 5 : lớp á cát có chiều dày từ 6 7,5 m; lớp 6: lớp sét có chiều dày từ $2,2-2,5$ m; lớp 7 : lớp cát có chiều dày từ 5,8 - $8 \mathrm{~m}$. Mặt bằng bố trí cọc khoan nhồi (28 cọc, đường kính $1 \mathrm{~m}$, chiều dài 64 m) (Hình 6).

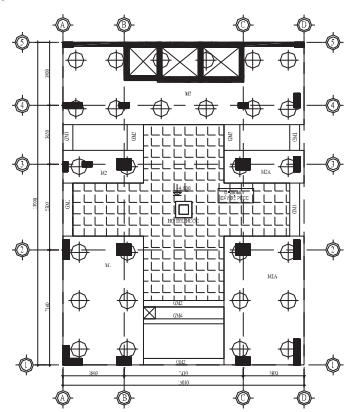

Hình 6. Mặt bằng bố trí móng cọc khoan nhồi công trình Khách sạn CANARY. 
- Công trình được mô hình 3D trong phần mềm ETABS 17 (Hình 7).

- Xuất toàn bộ phản lực chân cột, tổ hợp tải trọng, khai báo vật liệu từ phần mềm ETABS.

- Lưu dưới dạng file SAFE.F2K để Import vào phần mềm SAFE V16.

- Mô hình móng bè - cọc trong SAFE V16 theo dạng bè phẳng (Hình 8).

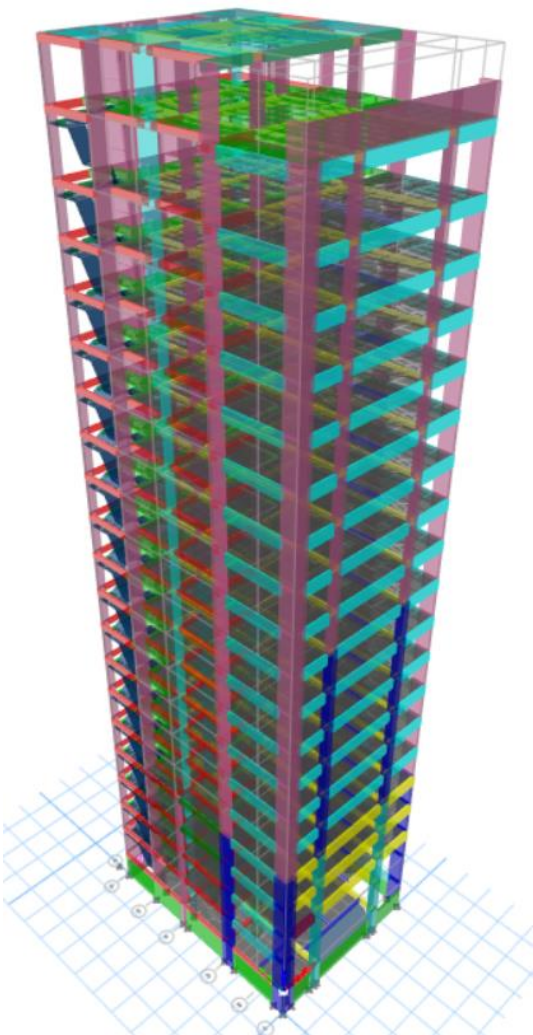

Hình 7. Mô hình 3D công trình Khách sạn CANARY.

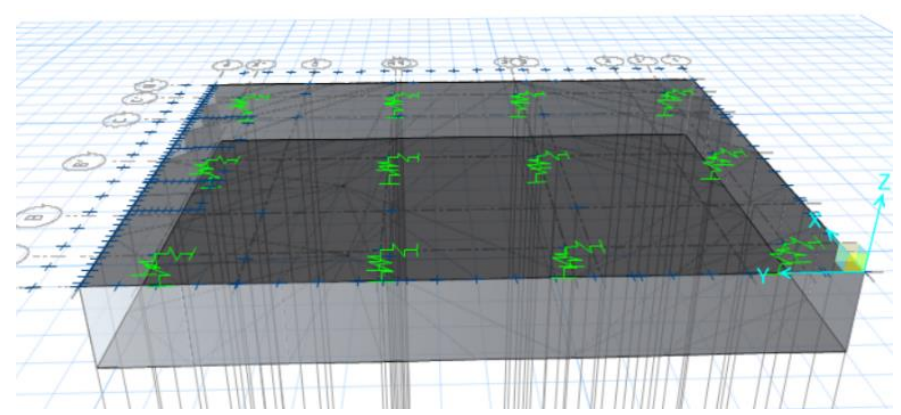

Hình 8. Mô hình móng bè cọc công trình Khách sạn CANARY.

\subsection{Hiệu quả móng bè - cọc}

Áp dụng phương pháp tính móng bè trên cọc ở hai công trình: công trình VĂN PHÒNG LÀM VIỆC và KHÁCH SẠN CANARY.

\section{- Công trình VĂN PHÒNG LÀM VIỆC}

Bảng 1.

So sánh lượng bê tông và thép Văn phòng làm việc.

\begin{tabular}{|c|c|c|c|}
\hline \multicolumn{4}{|c|}{ VĂN PHÒNG LÀM VIỆC } \\
\hline \multicolumn{2}{|c|}{ Cọc khoan nhồi } & \multicolumn{2}{|c|}{ Bè - Cọc } \\
\hline Bê tông $\mathrm{V}_{1}\left(\mathrm{~m}^{3}\right)$ & Thép $T_{1}$ (Tấn) & Bê tông $V_{2}\left(m^{3}\right)$ & Thép $T_{2}$ (Tấn) \\
\hline 268,37 & 17,20 & 237,63 & 10,44 \\
\hline \multicolumn{2}{|c|}{$\mathrm{V}_{\text {trung bình }}=\mathrm{V}_{1}-\mathrm{V}_{2}$} & \multicolumn{2}{|c|}{$\%$ bê tông $=V_{\text {trung bình }} / V_{1}$} \\
\hline \multicolumn{2}{|c|}{30,74} & \multicolumn{2}{|c|}{11,45} \\
\hline \multicolumn{2}{|c|}{$\mathrm{T}_{\text {trung bình }}=\mathrm{T}_{1}-\mathrm{T}_{2}$} & \multicolumn{2}{|c|}{$\%$ thép $=\mathrm{T}_{\text {trung bình }} / \mathrm{T}_{1}$} \\
\hline \multicolumn{2}{|c|}{6,76} & \multicolumn{2}{|c|}{39,30} \\
\hline
\end{tabular}

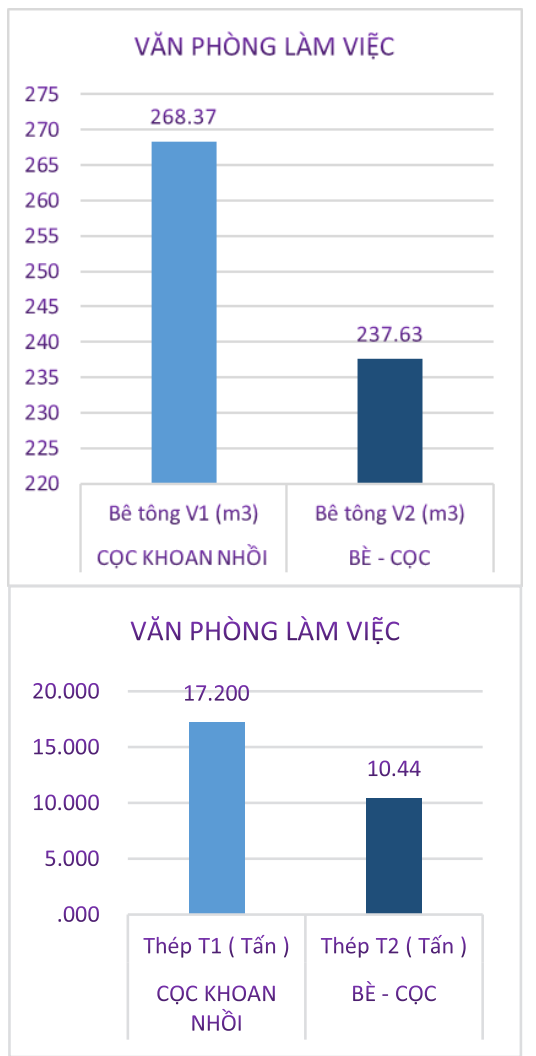

Hình 9. Sơ đồ so sánh lượng bê tông và thép Văn phòng làm việc. 


\section{Bảng 2.}

So sánh lượng bê tông và thép Khách sạn CANARY.

\begin{tabular}{|c|c|c|c|}
\hline \multicolumn{3}{|c|}{ KHÁCH SẠN CANARY } \\
\hline Bê tông $\mathrm{V}_{1}\left(\mathrm{~m}^{3}\right)$ & Thép $\mathrm{T}_{1}$ (Tấn) & Bê tông $\mathrm{V}_{2}\left(\mathrm{~m}^{3}\right)$ & Thép $\mathrm{T}_{2}$ (Tấn) \\
\hline $\mathbf{1 5 7 2 , 0 4}$ & $\mathbf{1 0 1 , 2}$ & $\mathbf{8 9 8 , 2 3}$ & $\mathbf{8 6 , 1 4}$ \\
\hline $\mathrm{V}_{\text {trung bình }}=\mathrm{V}_{1}-\mathrm{V}_{2}$ & $\%_{\text {bê tông }}=\mathrm{V}_{\text {trung bình }} / \mathrm{V}_{1}$ \\
\hline \multicolumn{2}{|c|}{$\mathbf{6 7 3 , 8 1}$} & \multicolumn{2}{|c|}{$\mathbf{4 2 , 8 6}$} \\
\hline \multicolumn{2}{|c|}{$\mathrm{T}_{\text {trung bình }}=\mathrm{T}_{1}-\mathrm{T}_{2}$} & $\%_{\text {thép }}=\mathrm{T}_{\text {trung bình }} / \mathrm{T}_{1}$ \\
\hline \multicolumn{2}{|c|}{$\mathbf{1 5 , 0 6}$} & $\mathbf{1 4 , 8 8}$ \\
\hline
\end{tabular}

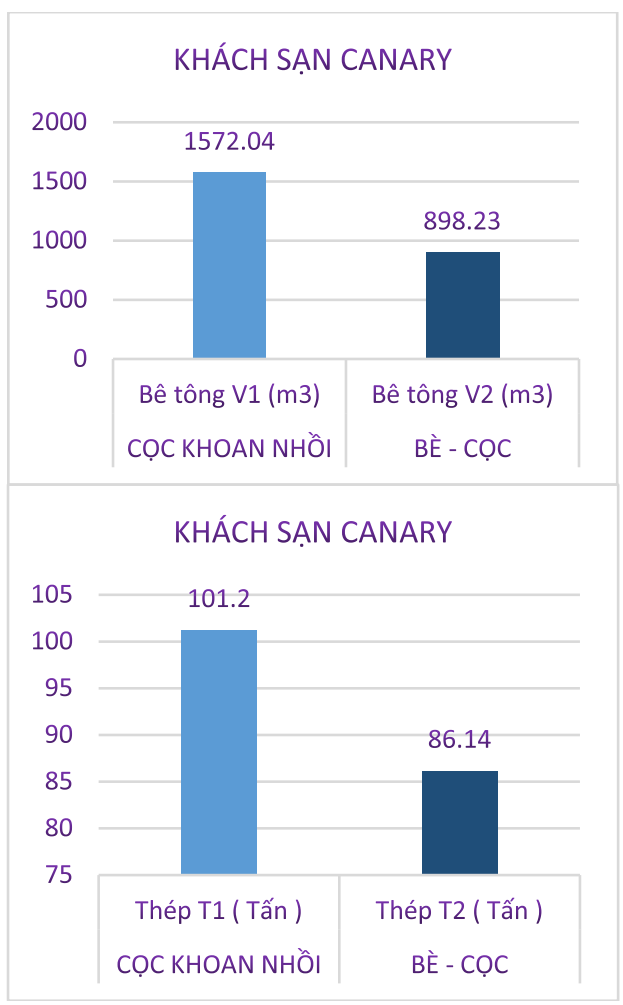

Hình 10. Sơ đồ so sánh lượng bê tông và thép Khách sạn CANARY.

+ Mặt bằng bố trí cọc khoan nhồi: 39 cọc, đường kính cọc là 0,5 m, chiều dài cọc là $17 \mathrm{~m}$.

+ Mặt bằng bố trí móng bè - cọc ép: bè dày $2 \mathrm{~m}$, gồm 36 cọc, tiết diện cọc 0,3 x 0,3 m, chiều dài cọc là $11,7 \mathrm{~m}$.
Móng bè - cọc trong công trình trên được bố trí các cọc chủ yếu ngay tại các vị trí có lực tập trung như: cột, vách cứng. Cho kết quả tỷ lệ chia tải như sau: bè chịu 17,8 \% tổng tải, cọc chịu 82,2 \% tổng tải. Kết quả tính toán lượng bê tông và cốt thép móng bè - cọc so với móng cọc khoan nhồi được thể hiện ở Bảng 1 và Hình 9.

Như vậy, công trình Văn phòng làm việc nếu sử dụng phương án móng bè - cọc sẽ tiết kiệm 11,45 \% bê tông và 39,3 \% thép so với phương án móng cọc khoan nhồi.

\section{- Công trình KHÁCH SẠN CANARY:}

+ Mặt bằng bố trí cọc khoan nhồi: 28 cọc, đường kính $1 \mathrm{~m}$, chiều dài $64 \mathrm{~m}$.

+ Mặt bằng bố trí móng bè - cọc: bè dày $3 \mathrm{~m}$, gồm 15 cọc khoan nhồi, đường kính cọc $0,5 \mathrm{~m}$, chiều dài cọc $49 \mathrm{~m}$.

Kết quả tỷ lệ chia tải như sau: bè chịu 12,8 \%, cọc chịu 87,2 \% tổng tải.

Kết quả tính toán lượng bê tông và cốt thép móng bè - cọc so với móng cọc khoan nhồi được thể hiện ở Bảng 2 và Hình 10 .

Như vậy công trình Khách sạn CANARY nếu sử dụng phương án móng bè - cọc sẽ tiết kiệm được 42,86 \% bê tông và 14,88 \% thép so với phương án móng cọc khoan nhồi.

\section{Kết luận}

Bài báo sử dụng phương pháp xét đến mối quan hệ tương hỗ giữa đất, bè, cọc và áp dụng các lý thuyết nghiên cứu gần đây đem lại hiệu quả đáng kể khi so sánh móng bè - cọc với móng cọc khoan nhồi. Trong thực tế kết cấu móng bè - cọc, nền đất dưới đáy bè đều tham gia vào quá trình chịu tải trọng công trình. Phương pháp tính toán móng bè - cọc này giúp giảm bớt được số lượng cọc, chiều dài cọc, tận dụng tối đa sức chịu tải cực hạn của cọc. Hệ móng bè - cọc còn giúp công trình giảm lún lệch, tăng khả năng chịu tải trọng ngang. Vì vậy, móng bè cọc nếu sử dụng phương pháp tính toán hợp lý sẽ là một hệ thống móng ưu việt, không chỉ hiệu quả về mặt kinh tế mà còn có tính ổn định cao. Việc đưa lý thuyết này vào quy phạm tính toán móng bè - cọc nói riêng và kết cấu công trình nói chung là một vấn đề cần thiết để nước ta không bị tụt hậu so với thế giới.

Tài liệu tham khảo

[1]. Lê Anh Hoàng, Nền và móng, tr 260-293, NXB Xây dựng, 2004.

[2]. Trần Quang Hộ, Giải Pháp Nền Móng Nhà Cao Tầng, tr 160-168, NXB ĐH quốc gia TP.HCM.

[3]. TCVN 9362: 2012: Tiêu chuẩn thiết kế nền nhà và công trình.

[4]. Poulos H.G. an approximate numerical analysis of pile raft interaction. International journal of Numerical and Analytical Methods in Geomechanics, Vol. 18, pp. 73-92, 1994. 